\title{
Innate Nonhost Immunity in Barley to Different Heterologous Rust Fungi Is Controlled by Sets of Resistance Genes with Different and Overlapping Specificities
}

\author{
Hossein Jafary, ${ }^{1,2}$ Les J. Szabo, ${ }^{3}$ and Rients E. Niks ${ }^{1}$ \\ ${ }^{1}$ Department of Plant Breeding, Wageningen University, P.O. Box 386, 6700 AJ Wageningen, The Netherlands; ${ }^{2}$ Agricultural \\ Research \& Education Organization, Plant Pests \& Diseases Research Institute P.O. Box 19395-1454 Tehran, Iran; ${ }^{3}$ Cereal \\ Disease Laboratory, Agricultural Research Service, United State Department of Agriculture, 1551 Lindig Avenue, St. Paul, \\ MN 55108, U.S.A.
}

Submitted 23 May 2006. Accepted 23 June 2006.

\begin{abstract}
We developed an evolutionary relevant model system, barley-Puccinia rust fungi, to study the inheritance and specificity of plant factors that determine to what extent innate nonhost immunity can be suppressed. A mapping population was developed from a cross between an experimental barley line (SusPtrit) with exceptional susceptibility to several heterologous (nonhost) rust fungi and regular, immune, cv. Vada. Seedlings were inoculated with five heterologous and two homologous (host) species of rust fungi. Resistance segregated quantitatively for each of the rust fungi. In total, 18 chromosomal regions were implicated. For each rust species, a different set of genes was effective. Of the $\mathbf{1 8}$ chromosomal regions, 11 were significantly effective to only one rust species and 7 were effective to more than one rust species, implying genetic linkage or pleiotropy. One resistance $(R)$ gene for hypersensitive resistance to Puccinia hordei-secalini was mapped, suggesting occasional contribution of $\boldsymbol{R}$ genes to nonhost resistance in barley. Quantitative trait loci (QTLs) with effects to multiple rust fungi did not tend to be particularly effective to rust species that were phylogenetically related, as determined from their internal transcribed spacer sequence. We suggest that the QTLs described here play a role as specific and quantitative recognition factors that are specifically negated by the rust to successfully suppress innate immunity.
\end{abstract}

Additional keywords: basal resistance, Hordeum vulgare, partial resistance.

In plants and animals, innate immunity, especially resistance to nonhost pathogens, is induced by recognition of pathogenassociated molecular patterns (PAMPs) (Zipfel and Felix 2005) which are generally occurring and conserved compounds, such as chitin in fungi and flagellins of bacteria. The innate immunity system of animals and plants recognize PAMPs through pattern recognition receptors (PRRs), such as FLS2 in Arabidopsis, which is involved in flagellin perception of gramnegative bacteria and has a highly conserved structure (GomezGomez and Boller 2000). One of the most abundant and conserved bacterial proteins, elongation factor $\mathrm{Tu}(\mathrm{EF}-\mathrm{Tu})$, also can be recognized as a PAMP by Arabidopsis plants (Kunze et

Corresponding author: Rients E. Niks; E-mail: Rients.Niks@wur.nl al. 2004). Zipfel and associates (2006) recently showed that a receptor kinase called EFR is essential for EF-Tu perception in Arabidopsis. Because host pathogens also contain PAMPs, they apparently have developed a way to suppress basal defense in their susceptible host plant. For example, Pseudomonas syringae pv. tomato contains flagellin, which indeed briefly initiates a basal defense but, within approximately $6 \mathrm{~h}$, suppresses this response (Kang et al. 2003), probably by delivering a large number of effector proteins into the plant cells (Kang et al. 2003; Kim et al. 2005). Rust fungi probably suppress or prevent elicitation of basal defense in their hosts by interfering with communication between the host plant plasmalemma and cell wall (Mellersh and Heath 2001). Basal defense of plants to rust fungi in many cases expresses itself as failed haustorium formation, without induction of a hypersensitive response (HR) (Mellersh and Heath 2001). If PAMPs occur universally in whole classes of pathogens, and PRRs that perceive PAMPs are conserved in plants (Gomez-Gomez and Boller 2000; Kunze et al. 2004; Zipfel and Felix 2005), then one of the challenges is to understand how pathogens are able to suppress basal defense in their host plant species but not in closely related nonhost species. Given the presumed conservation of PAMPs and PRRs, it is surprising, for example, that the rye leaf rust fungus Puccinia recondita is able to suppress basal defense in its host species rye (Secale cereale) but not in wheat (Triticum aestivum) (Niks and Dekens 1991), although rye and wheat are closely related and able to hybridize. Obviously, there is a range of specific factors in the pathogen and in the plant that determine the extent to which basal defense can be suppressed. Even within a host species, there appears to be genetic variation in the degree to which basal defense can be suppressed by the pathogen. For example, in the barley (Hordeum vulgare)barley leaf rust ( $P$. hordei) system (Niks 1986a), some barley cultivars have a high level of non-HR polygenically inherited resistance, which has been termed "partial resistance" by Parlevliet (1975). In such partially resistant barley genotypes, the barley leaf rust fungus seems to be less effective in suppressing the basal resistance reaction.

The objectives of this study were to investigate the inheritance and specificity of plant factors that determine the degree of suppression of basal defense by host and (near) nonhost pathogens and to determine whether there is a correlation between phylogenetic relationship of the fungal pathogens and specificity of these plant factors. We followed a forward genet- 
ics approach using the barley cv. Vada and recently developed experimental line SusPtrit. The latter accession, which is fully susceptible to the wheat leaf rust fungus $P$. triticina, was developed by a selection program for increased susceptibility to $P$. triticina (Atienza et al. 2004). Interestingly, this line was partially or fully susceptible to some other heterologous rust fungal pathogens as well. Rust fungi used in this study represent three taxonomic groups: i) $P$. hordei complex ( $P$. hordei and $P$. hordei-murini); ii) $P$. recondita/P. persistens complex ( $P$. hordei-secalini, $P$. persistens, and $P$. triticina [from bread wheat]), and iii) $P$. triticina-"duri" (from durum wheat) and $P$. graminis ( $P$. graminis f. sp. lolii and $P$. graminis f. sp. tritici). Cultivated barley (H. vulgare) is a host for $P$. hordei and $P$. graminis f. sp. tritici but a near-nonhost to the other rust fungal species and formae speciales (i.e., only a small fraction of barley accessions allowed some reproduction of these rusts fungi) (Atienza et al. 2004).

\section{RESULTS}

\section{Marker analysis and map construction.}

In total, 448 markers - amplified fragment length polymorphism (AFLP), simple sequence repeat (SSR), and two morphological markers-were assembled into 18 linkage groups at a $\log$ of the likelihood ratio (LOD) threshold of 8.0, and could be united into 7 linkage groups with a total map length of 972 centimorgans $(\mathrm{cM})$. The average marker distance on the extracted skeletal map used for quantitative trait locus (QTL) mapping was $5.4 \mathrm{cM}$. For those markers that had been mapped in L94 $\times$ Vada or other populations, the order and relative position in the linkage groups was consistent with previously published maps (Liu et al. 1996; Qi et al. 1998b; Ramsay et al. 2000).

\section{Disease tests with rust species and isolates to which barley is a near-nonhost.}

For all pathogens tested, frequency of visible infection sites (FVIS; the number of both flecks and pustules per square centimeter), infection frequency (IF; the number of pustules per square centimeter), and relative infection frequency (RIF; the number of pustules per square centimeter relative to the IF of the susceptible parent SusPtrit in the same box) showed continuous and quantitative segregation, indicating polygenic inheritance of the resistance. Frequency distributions of phenotypes for FVIS are shown in Figure 1.

The infection phenotypes for four heterologous rust fungi (P. triticina, P. persistens, $P$. hordei-murini, and $P$. hordeisecalini) were nearly immune for Vada. SusPtrit was the most susceptible accession. However, in the case of $P$. graminis $\mathrm{f}$. sp. lolii, some recombinant inbred lines (RILs) showed higher levels of susceptibility and resistance compared with the respective parental lines, indicating that the two parents carried both susceptibility and resistance alleles to this rust fungus. Resistance to $P$. triticina (three isolates), P. persistens, $P$. hordei-murini, and $P$. graminis $\mathrm{f}$. sp. lolii was not associated with a clear HR. For P. hordei-secalini, 59\% of RILs showed HR response with hardly any pustule development (Fig. 2Ad). The remaining RILs varied in level of non-HR resistance (Fig. $2 \mathrm{Aa}, \mathrm{Ab}$, and $\mathrm{Ac})$. The HR phenotypes varied from restricted chlorosis (chlorotic spots) to extensive chlorosis (chlorosis of most of the leaf) and from small brown lesions (Fig. 2Ad) to large confluent necrotic flecks. The levels of infection established by $P$. triticina and $P$. persistens ranged from immune (no pustules and fewer than 3 flecks $/ \mathrm{cm}^{2}$ ) to fully susceptible (maximum 92 and 76 sporulating pustules per square centimeter, respectively). However, for $P$. hordei-murini, a lower level of susceptibility was observed in SusPtrit and in the most susceptible RILs compared with the other heterologous rust fungi.
Disease test with two rust species to which barley is a host.

The RIL population showed a quantitative segregation for susceptibility to $P$. hordei isolate 1.2 .1 (Fig. 1G). The relative latency period (RLP) values of RILs in three replications did not indicate transgressive segregation in this population. SusPtrit was as susceptible as our long-term most susceptible standard line L94 and, in some cases, slightly more susceptible. The mapping population showed a quantitative segregation for susceptibility to $P$. graminis f. sp. tritici as well (Fig. 2B). The pustules of neighboring infections in more susceptible RILs often merged and, in more resistant RILs, single infection sites often produced two or more tiny pustules, making IF an inaccurate measure for the level of resistance to $P$. graminis $\mathrm{f} . \mathrm{sp}$. tritici (Fig. 2B). Therefore, the area covered with lesions, including the pale green/yellowish areas surrounding pustules, was used as an alternative index to quantify susceptibility of RILs. In a random subset of RILs, correlation between IF and area covered with lesions was positive and highly significant $(r$ $=0.91$ ). Some of the individuals showed higher susceptibility or resistance compared with the two parental lines, indicating transgressive segregation to $P$. graminis $\mathrm{f}$. sp. tritici in this mapping population.

\section{Phylogenetic analysis of rust fungi.}

Parsimony analysis of internal transcribed spacer (ITS) sequence data from 20 rust isolates resulted in four optimal trees with a tree length of 262 (Fig. 3). Distance analysis using the neighbor-joining method (Kimura 2-parameter) resulted in a tree with identical topography. DNA sequences from rust samples used in this study grouped into three distinct and wellsupported clades (Fig. 3). Clade I consisted of the barley leaf rusts $P$. hordei (H. vulgare) and $P$. hordei-murini (H. murinum). These two rusts are closely related to onion and garlic rust $(P$. allii), which forms a sister group within clade I. The remaining barley leaf rust, $P$. hordei-secalini ( $H$. secalinum), grouped in clade III, which also contained $P$. persistens, $P$. triticina, and $P$. triticina-"duri". P. bromina (Bromus sp.), and P. cerinthesagropyrina (Agropyron sp.) formed a sister group within clade III. Three collections of stem rust ( $P$. graminis) formed clade IV, which was divided into two subgroups, $P$. graminis f. sp. tritici and $P$. graminis f. sp. lolii and $P$. graminis f. sp. avenae. $P$. holcina, $P$. coronata (crown rust), and $P$. striiformis (stripe rust) formed distinct clades II, V, and VI, respectively.

\section{Correlations among quantified traits for different rusts.}

Correlation coefficients $(r)$ among the infection parameters measured in the mapping population for nonhost and partial resistance to 10 isolates representing seven rust species are shown in Table 1. In the case of association, a negative correlation would be expected between RLP to $P$. hordei and FVIS of other rust fungi. The highest negative correlation was between RLP to $P$. hordei and FVIS to $P$. persistens $(r=-0.40)$, indicating that at least some of the genes for resistance to these rusts either are linked or have pleiotropic effects. The highest positive correlation was observed between different isolates of $P$. triticina ( $r=0.62$ to 0.73 ). Correlation between two formae speciales of $P$. graminis was intermediate $(r=0.43)$. Among the three phylogenetic groups of rusts, the $P$. triticina and the $P$. graminis group showed the highest correlation (Table 1).

\section{QTLs mapped for nonhost and partial resistance.}

QTL mapping for nonhost resistance was performed using eight isolates belonging to five heterologous rust species and three evaluated traits: IF, FVIS, and RIF. In all cases, FVIS and IF were closely correlated ( $r=0.73$ to 0.99 ), resulting in the same QTLs identified for both parameters. Due to homogeneous distribution of spores on the leaves of inoculated plants, 
the same QTLs were identified for RIF and IF traits as well. The LOD scores for QTLs were generally higher for FVIS than for IF; therefore, only mapping data for parameter FVIS are presented (Table 2; Fig. 4). For all heterologous rust species except $P$. graminis f. sp. lolii, alleles for resistance originated from Vada and susceptibility alleles from the susceptible parent SusPtrit. For the latter rust species, one QTL allele for resistance originated from Vada and two from SusPtrit (Table 2). The qualitative segregation for hypersensitivity against $P$. hordei- secalini (Fig. 2A) allowed mapping of this feature by Joinmap. This demonstrated that a major gene at $58 \mathrm{cM}$ on chromosome $5(1 \mathrm{H})$ was responsible for the HR.

Four QTLs were found to be effective to all three $P$. triticina isolates, and one QTL seemed effective to only the Flamingo isolate because the LOD profile in that region was flat in the tests with both other isolates of this rust species. The contribution of seven barley chromosomes in resistance to the rust species varied from one QTL effective to only one rust species
A

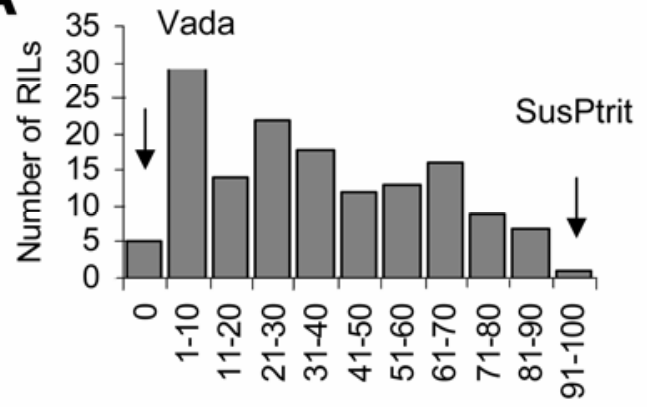

Visible Infection Sites (VIS)
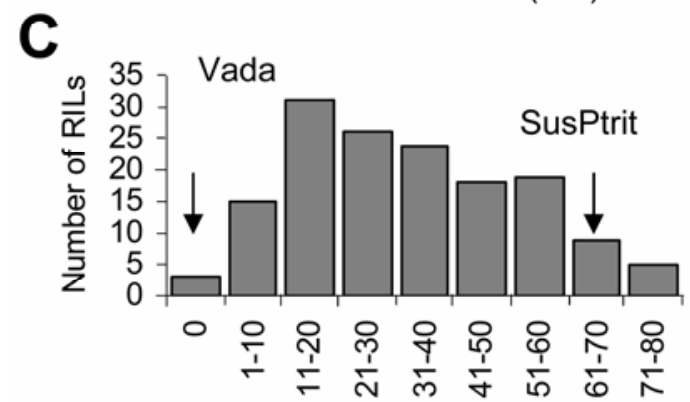

Visible Infection Sites (VIS)

E

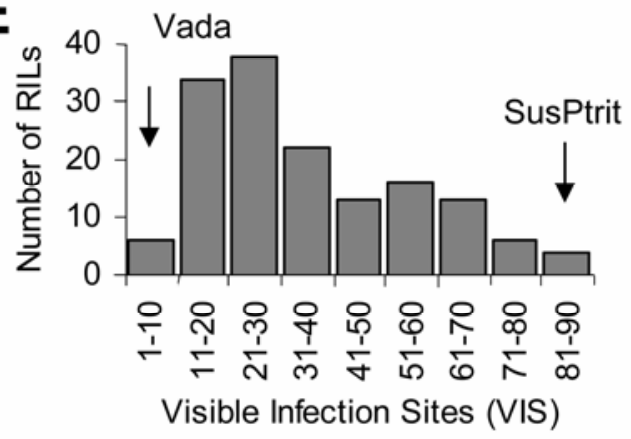

G

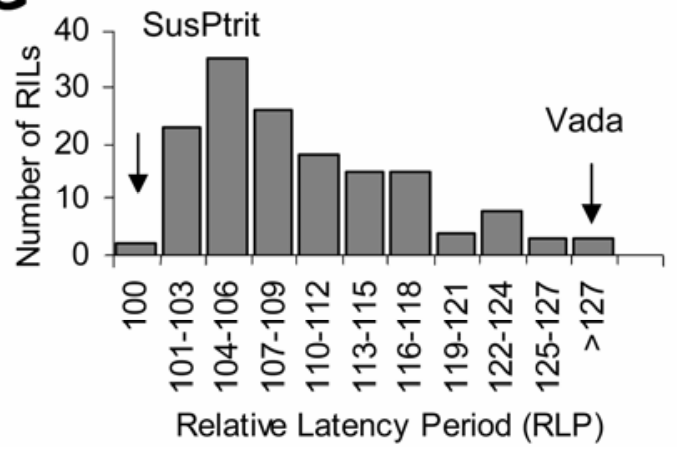

B

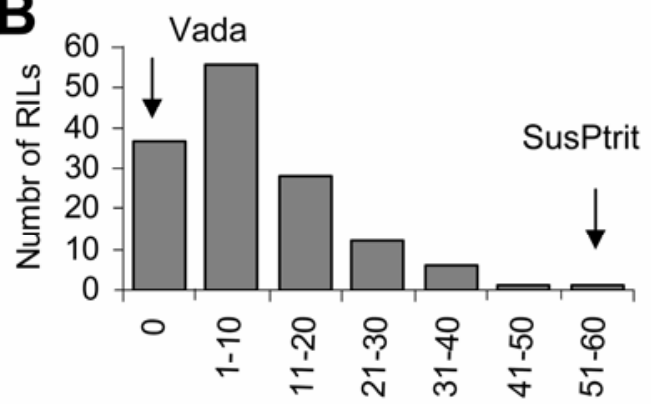

Visisble Infection Sites (VIS)

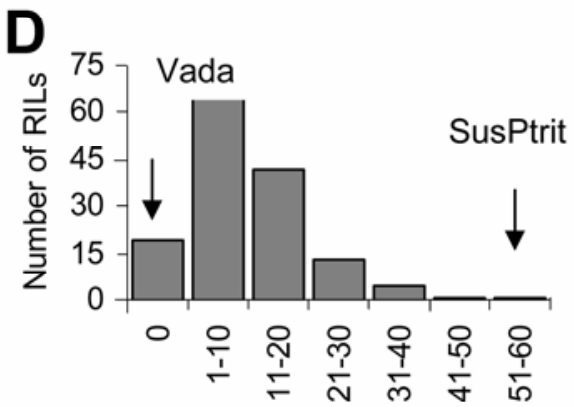

Visible Infection Sites (VIS)

$\mathbf{F}$

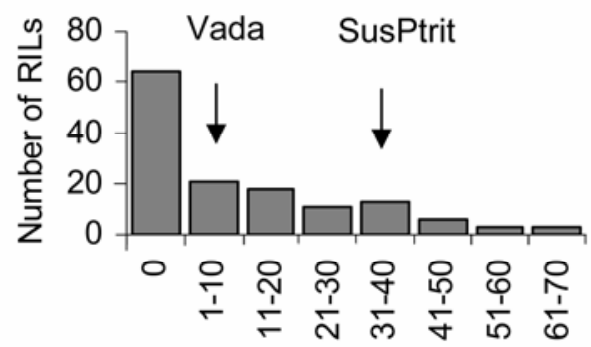

Visible Infection Sites (VIS)

H

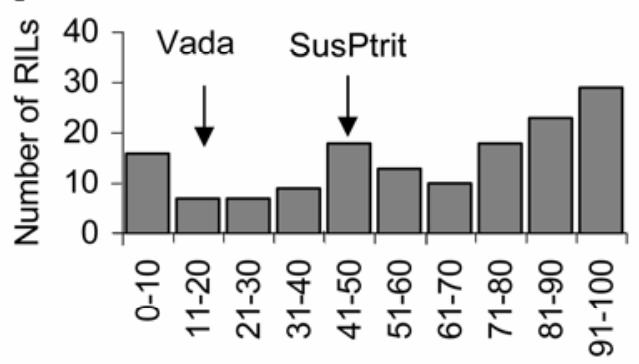

$\%$ Area covered with lesions (ACL)

Fig. 1. Frequency distribution of phenotypes for resistance to eight rust species in barley mapping population Vada $\times$ SusPtrit. Values of the two parental lines are shown by arrow. A, Puccinia triticina (Flamingo isolate); B, P. triticina from Triticum durum; C, P. persistens, D, P. hordei-murini; E, P. hordeisecalini; $\mathbf{F}$, P. graminis f. sp. lolii; $\mathbf{G}$, P. hordei; and $\mathbf{H}$, P. graminis f. sp. tritici. 
(chromosome 4) to four QTLs effective to seven different rust species (chromosome 1).

In the same way as described above, QTL mapping was performed for RLP of $P$. hordei. The most effective QTL to $P$. hordei was mapped at the bottom of chromosome 2 (Table 2; Fig. 4). This QTL was mapped to a position similar to that of a QTL reported by Qi and associates (1998a) with identical flanking markers. Two other QTLs with minor effect were mapped on chromosomes 1 and 3. Their confidence interval did not overlap with QTLs mapped in the L94 $\times$ Vada mapping population. Five QTLs were mapped for resistance to $P$. graminis f. sp. tritici; two for resistance were contributed by SusPtrit and three by Vada (Table 2). Two QTLs for partial resistance to $P$. hordei and three QTLs for $P$. graminis f. sp. tritici colocated with QTLs effective to heterologous rusts (Table 2; Fig. 4). Three chromosomal regions were mapped with LOD scores lower than the LOD threshold but significant to other rusts (Table 2).

\section{DISCUSSION}

\section{Barley-rust pathosystem as a model}

to study the genetics of nonhost resistance.

There is a lack of good genetic systems to study the genetic basis of nonhost resistance. At present, mutagenesis and transformation are the main approach to study the genetic basis of nonhost resistance in the model plant Arabidopsis thaliana. By mutagenesis, major genes have been demonstrated to be involved in nonhost resistance (Lu et al. 2001; Wildermuth et al. 2001). A forward genetics approach, however, has the advantage of allowing identification of evolutionary relevant qualita- tive and quantitative factors that determine the elicitation of resistance or the degree of suppression of basal defense by host and nonhost pathogens. However, by definition, crossings between host and nonhost species are interspecific crosses that, if feasible at all, nearly always suffer from sterility, abnormal growth, and poor seed viability and, therefore, are unsuitable for studying the genetics of nonhost resistance. Therefore, we make use of the fact that barley is a marginal host to some heterologous rust species. Only a few, mainly exotic, $H$. vulgare accessions are somewhat susceptible at the seedling stage to some grass and cereal rust species (Atienza et al. 2004). This allowed us to develop a barley research line, SusPtrit, in which susceptibility genes to heterologous rust species were accumulated (Atienza et al. 2004). This line was used as one of the parents in the presently analyzed mapping population.

\section{Genetics of nonhost resistance.}

In total, 18 chromosomal regions segregated for resistance in the studied mapping population, of which 11 were significantly effective to only one rust species. These regions were spread all over the genome, but tended to map especially to chromosome 1 $(7 \mathrm{H})$ and chromosome $5(1 \mathrm{H})$, (both four regions) and least to chromosome $4(4 \mathrm{H})$ (one region). Two regions, one at the bottom of chromosome $1(125$ to $140 \mathrm{cM})$ and another at the centromeric region of chromosome $6(50$ to $65 \mathrm{cM})$ showed multiple effects to five and four rust species, respectively (Fig. 4). Effects to two or more rust species can be due to either close linkage of genes or pleiotropy. Basal resistance to heterologous pathogens also has been reported to inherit polygenically in wild lettuce (Lactuca saligna), which is a nonhost to Bremia lactucae (Jeuken and Lindhout 2002). Previous evidence already sug-
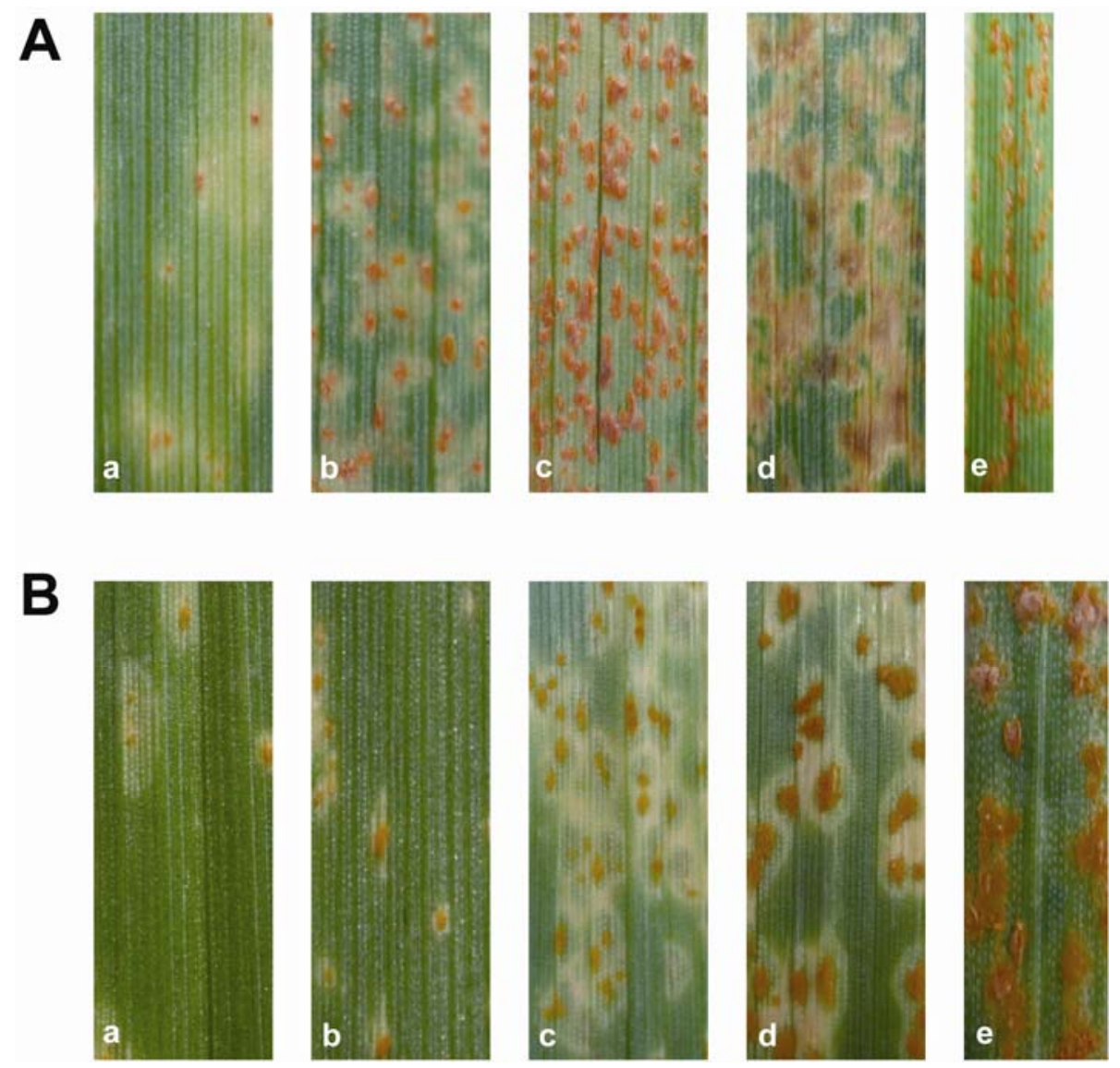

Fig. 2. Segregation of recombinant inbred lines (Vada $\times$ SusPtrit) for nonhost resistance to Puccinia hordei-secalini and host resistance to $P$. graminis f. sp. tritici. A, Quantitative (a, b and c) and qualitative (d) segregation to P. hordei-secalini (e = host plant) $\mathbf{B}$, Quantitative segregation (a, $\mathrm{b}$, and $\mathrm{c}$ ) to P. graminis f. sp. tritici $(\mathrm{d}=$ abaxial side of infected leaf, $\mathrm{e}=$ susceptible wheat line "Morocco"). 
gested that nonhost resistance of barley is due to additive effects of genes with effectiveness to several heterologous rusts and to genes with a rust species-specific effect (Atienza et al. 2004; Hoogkamp et al. 1998). The present research also indicates that linkage between rust-specific genes may have contributed to an apparent wide spectrum of effectiveness.
Reliability of QTL mapping.

In order to evaluate the reliability of QTL detection, we performed three replications for disease test experiments and compared QTLs detected in each replication. Only repeated detection of QTLs was considered reliable. One QTL for $P$. persistens (LOD value 2.9) occurred in only one replication

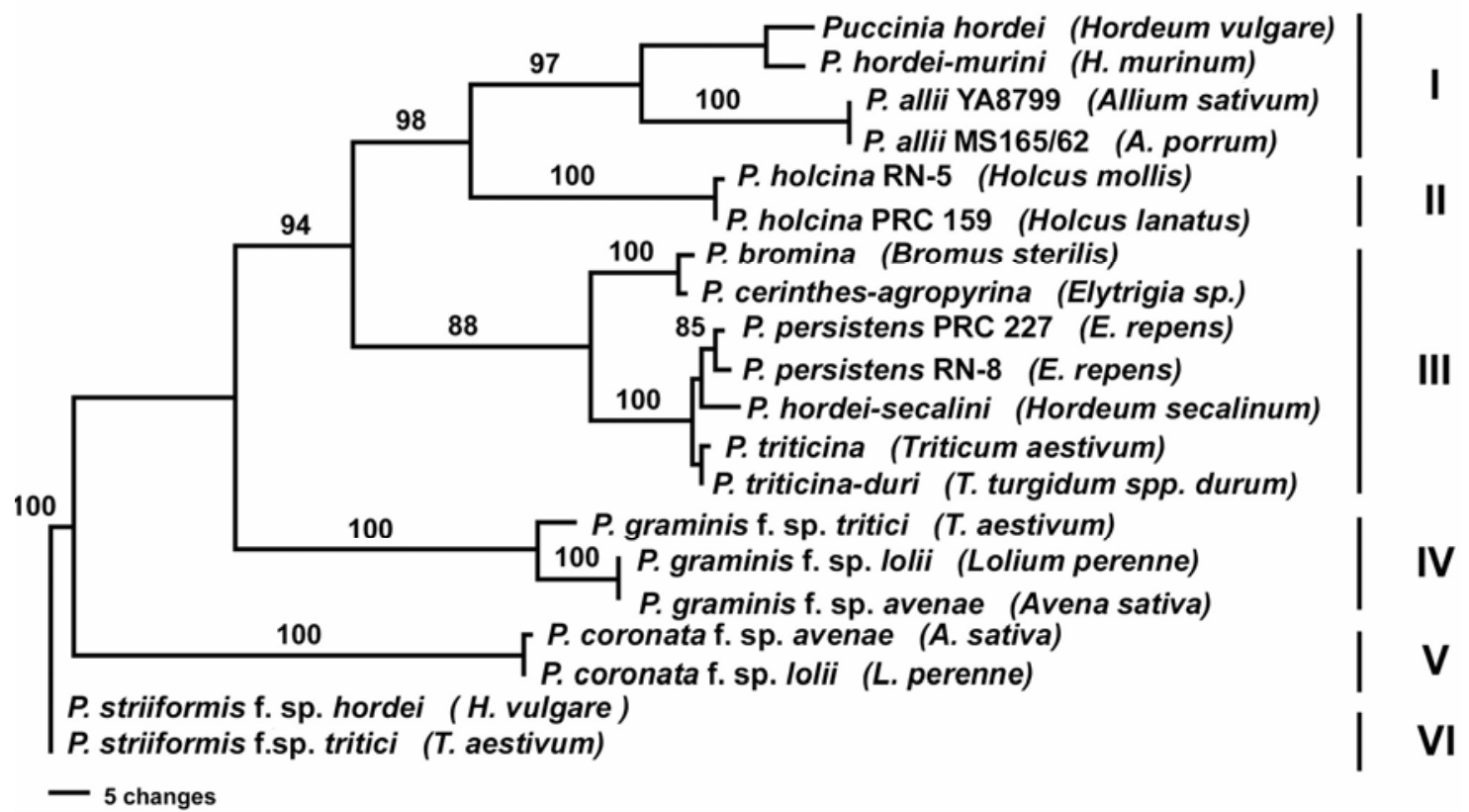

Fig. 3. Parsimony tree from the analysis of nuclear ribosomal internal transcribed spacer (ITS) sequence data of selected cereal and grass rusts. Phylogenetic analysis resulted in four optimal trees, one of which is shown (tree length of 262 steps, Consistency index $=0.7634$, homoplasy index $=0.2366$, retention index $=0.8839$, and rescaled consistency index $=0.6747$ ). Numbers above branches indicate percentage of congruent clusters in 1,000 bootstrap trials and only values above $80 \%$ are shown. Rust hosts are indicated in parentheses. Clades are indicated along the right hand side. Puccinia striiformis DNA sequences were used as outgroup.

Table 1. Correlation coefficients $(r)$ among infection parameters expressing level of resistance of 152 recombinant inbred lines of Vada $\times$ SusPtrit, for 10 isolates belonging to seven rust species ${ }^{\mathrm{a}}$

\begin{tabular}{|c|c|c|c|c|c|c|c|c|c|c|}
\hline $\begin{array}{l}\text { Criteria } \\
\text { measured }\end{array}$ & $\begin{array}{c}\text { RLP } \\
\text { (Puccinia } \\
\text { hordei) }\end{array}$ & $\begin{array}{c}\text { FVIS } \\
\text { (P. hordei- } \\
\text { murini) }\end{array}$ & $\begin{array}{c}\text { FVIS } \\
\text { (P. triticina) } \\
\text { Flamingo }\end{array}$ & $\begin{array}{l}\text { FVIS } \\
\text { (P. triticina) } \\
\text { Swiss }\end{array}$ & $\begin{array}{c}\text { FVIS } \\
\text { (P. triticina) } \\
\text { French }\end{array}$ & $\begin{array}{c}\text { FVIS } \\
\text { (P. triticina- } \\
\text { "duri") }\end{array}$ & $\begin{array}{c}\text { FVIS } \\
(P . \\
\text { persistens })\end{array}$ & $\begin{array}{c}\text { IF } \\
\text { (P. hordei- } \\
\text { secalini) }\end{array}$ & $\begin{array}{l}\text { Inf. Area } \\
\text { (P. graminis } \\
\text { f. sp. tritici) }\end{array}$ & $\begin{array}{c}\text { FVIS } \\
\text { (P. graminis } \\
\text { f. sp. lolii) }\end{array}$ \\
\hline $\begin{array}{l}\operatorname{RLP}(P . \\
\text { hordei })\end{array}$ & $\ldots$ & $\ldots$ & $\ldots$ & $\ldots$ & & $\ldots$ & & $\ldots$ & & \\
\hline $\begin{array}{r}\text { FVIS }(P . \\
\text { hordei- }\end{array}$ & & & & & $\cdots$ & $\cdots$ & $\cdots$ & $\cdots$ & $\cdots$ & $\cdots$ \\
\hline $\begin{array}{c}\text { murini) } \\
\text { FVIS }(P . \\
\text { triticina })\end{array}$ & -0.11 & $\ldots$ & $\ldots$ & $\ldots$ & $\ldots$ & $\ldots$ & $\ldots$ & $\ldots$ & $\ldots$ & $\ldots$ \\
\hline $\begin{array}{c}\text { Flamingo } \\
\text { FVIS ( } P . \\
\text { triticina) }\end{array}$ & -0.22 & 0.34 & $\ldots$ & $\ldots$ & $\ldots$ & $\ldots$ & $\ldots$ & $\ldots$ & $\ldots$ & $\ldots$ \\
\hline $\begin{array}{l}\text { Swiss } \\
\text { FVIS ( } P \text {. } \\
\text { triticina })\end{array}$ & -0.30 & 0.37 & 0.73 & $\ldots$ & $\ldots$ & $\ldots$ & $\ldots$ & $\ldots$ & $\ldots$ & $\ldots$ \\
\hline $\begin{array}{l}\text { French } \\
\text { FVIS }(P \text {. } \\
\text { triticina }\end{array}$ & -0.30 & 0.33 & 0.70 & 0.69 & $\ldots$ & $\ldots$ & $\ldots$ & $\ldots$ & $\ldots$ & $\ldots$ \\
\hline $\begin{array}{l}\text { “duri”) } \\
\text { FVIS (P. }\end{array}$ & -0.27 & 0.33 & 0.62 & 0.69 & 0.50 & $\ldots$ & $\ldots$ & $\ldots$ & $\ldots$ & $\ldots$ \\
\hline $\begin{array}{l}\text { persistens }) \\
\text { IF (P. hordei- }\end{array}$ & -0.40 & 0.36 & 0.49 & 0.54 & 0.53 & 0.51 & $\ldots$ & $\ldots$ & $\ldots$ & $\ldots$ \\
\hline $\begin{array}{l}\text { secalini }) \\
\text { Inf. Area }(P .\end{array}$ & -0.14 & 0.22 & 0.47 & 0.44 & 0.40 & 0.48 & 0.46 & $\ldots$ & $\ldots$ & $\ldots$ \\
\hline $\begin{array}{l}\text { sp. tritici) } \\
\text { FVIS ( } P \text {. }\end{array}$ & -0.12 & 0.28 & 0.44 & 0.45 & 0.34 & 0.34 & 0.42 & 0.16 & $\ldots$ & $\ldots$ \\
\hline $\begin{array}{l}\text { graminis I. } \\
\text { sp. lolii) }\end{array}$ & -0.14 & 0.20 & 0.34 & 0.33 & 0.35 & 0.21 & 0.17 & 0.17 & 0.43 & $\ldots$ \\
\hline
\end{tabular}

${ }^{\mathrm{a}} \mathrm{RLP}=$ relative latency period, FVIS $=$ frequency of visible infection site, IF = infection frequency, and Inf. Area = percentage of area covered by lesions. Correlation coefficients 0.45 and higher are highlighted in bold. 
and, therefore, was not included. Four QTLs effective to different isolates of $P$. triticina (Table 2) were mapped nine times (three isolate $\times$ three replications) at identical positions, indicative of a high repeatability of QTL analysis. In addition, for each rust species, we used three parameters (IF, FVIS, and RIF) to estimate resistance of RILs and we mapped the same QTLs for all three parameters with only some small changes in LOD values. For all the mapped QTLs, the parental provenance of the resistance allele was as expected (i.e., from Vada, except in case of $P$. graminis f. sp. lolii, where transgression occurred). This lends confidence that the QTLs found are not due to random experimental errors.

\section{Host and nonhost resistance: possible associations in mechanisms and genetics.}

Heterologous rust fungi that are pathogenic to members of Gramineae generally are well able to find and penetrate stomata on nonhost grass and cereal species (Niks 1986b) but usually are hardly able to form haustoria (Niks 1983, 1986b; Niks and Rubiales 2002). It is likely that prevention of haustorium formation, which is associated with papilla formation, is indicative for lack of basic compatibility (Panstruga 2003). Niks (1989) showed that the heterologous rye leaf rust fungus $P$. recondita could form haustoria in barley mesophyll cells only when $P$. hordei had already formed a haustorium in that cell. This suggests that pathogens should suppress innate immunity, as put forward by Mellersh and Heath (2001). Also, in some host genotypes, haustorium formation by its own regular pathogen can be relatively poor. $P$. hordei is much more successful in formation of haustoria in the susceptible line L94 than in the cultivar Vada (Niks 1983, 1986a). Interestingly, there seemed to be a moderate association between level of partial resistance to $P$. hordei and level of resistance to two heterologous rust fungi (Hoogkamp et al. 1998; Zhang et al. 1994). In the present study, two QTLs (out of three) for partial resistance to $P$. hor- dei and three QTLs (out of five) for P. graminis f. sp. tritici showed double or multiple effectiveness to some heterologous rust species (Table 2; Fig. 3), suggesting a genetic association between host and nonhost resistance in barley, both acting at the level of basic compatibility and its complementary phenomenon, basal resistance.

Our data suggest that resistance $R$ genes also may contribute to nonhost resistance. The $R$ gene that we mapped on chromosome $5(1 \mathrm{H})$ for $P$. hordei-secalini showed similarities in its phenotype (HR reaction) and the genetics (monogenic inheritance) with the $R$ genes, named $R p h$, in barley to $P$. hordei that cause a posthaustorial HR. Remarkably, in that region, no $R p h$ genes to $P$. hordei have been reported. In some barley germ plasm accessions (Atienza et al. 2004), many visible infection sites were found after inoculation with heterologous rust species, suggesting a fair colonization and, hence, a relatively successful haustorium formation, but followed by HR. These accessions may contain a relatively low gene dose for basal resistance, but may harbor a back-up resistance through one or more $R$ genes, such as the gene that Vada possesses against $P$. hordei-secalini. We will address the role of $R$ genes in nonhost resistance in a future study.

\section{Evolutionary perspective of innate immunity in barley.}

Adaptation of biotrophic pathogens to a restricted number of host species can be regarded as a consequence of the coevolution of these pathogens with their host plant species (ThordalChristensen 2003). Therefore, one may wonder about a possible association of evolutionary distance and host status to a certain potential pathogen. In case the systematic relationship of a pathogen reflects that of its host, their evolutionary histories also may be linked (Wyand and Brown 2003). It seems reasonable to assume that a cereal ancestor carried some rust species that diverged along with the radiation of various descendant cereal and grass species. The rust may have special-

Table 2. Log of the likelihood ratio (LOD) values of regions on barley chromosomes conferring resistance to eight different rusts ${ }^{\mathrm{a}}$

\begin{tabular}{|c|c|c|c|c|c|c|c|c|c|c|}
\hline \multirow[b]{2}{*}{ Chr. ${ }^{\mathrm{c}}$} & \multirow[b]{2}{*}{ Pos. $(\mathrm{cM})^{\mathrm{c}}$} & \multicolumn{9}{|c|}{ Rust species $^{b}$} \\
\hline & & P.hor & P.hor-mur & P.tri ${ }^{\mathrm{d}}$ & P.duri & P.per & P.hor-sec & P.gram-tri & P.gram-lol & Total \\
\hline \multirow[t]{5}{*}{$1(7 \mathrm{H})$} & 65 to 75 & $\ldots$ & $\ldots$ & $\ldots$ & $\ldots$ & $\ldots$ & 4.2 & $\ldots$ & $\ldots$ & 1 \\
\hline & 85 to 100 & $\ldots$ & $\ldots$ & 8 & $\ldots$ & 4.4 & $\ldots$ & $\ldots$ & $\ldots$ & 2 \\
\hline & 105 to 110 & 2.7 & $\ldots$ & $\ldots$ & $\ldots$ & $\ldots$ & $\ldots$ & $\ldots$ & $\ldots$ & 1 \\
\hline & 120 to 135 & $\ldots$ & 5 & 7 & 7 & 4.2 & $\ldots$ & 5 & $\ldots$ & 5 \\
\hline & 90 to 100 & $\ldots$ & $\ldots$ & $3.9^{\mathrm{e}}$ & $\ldots$ & & $\ldots$ & $\ldots$ & $\ldots$ & 1 \\
\hline \multirow[t]{2}{*}{$2(2 \mathrm{H})$} & 130 to 140 & 12 & $\ldots$ & $\ldots$ & $\ldots$ & 5.6 & & & $\ldots$ & 2 \\
\hline & 1 to 20 & $\ldots$ & $\ldots$ & $\ldots$ & $\ldots$ & 3.2 & 2.1 & 2.2 & $\ldots$ & 3 \\
\hline \multirow[t]{2}{*}{$3(3 \mathrm{H})$} & 40 to 60 & $\ldots$ & 3.1 & $\ldots$ & $\ldots$ & $\ldots$ & $\ldots$ & $\ldots$ & $\ldots$ & 1 \\
\hline & 100 to 120 & 3 & $\ldots$ & 3.8 & $\ldots$ & $\ldots$ & $\ldots$ & $\ldots$ & $\ldots$ & 2 \\
\hline \multirow[t]{2}{*}{$4(4 \mathrm{H})$} & 15 to 30 & $\ldots$ & $\ldots$ & $\ldots$ & $\ldots$ & 2.8 & $\ldots$ & $\cdots$ & $\begin{array}{l}\cdots \\
\ldots\end{array}$ & 1 \\
\hline & 20 to 35 & $\ldots$ & 4 & $\ldots$ & $\ldots$ & $\ldots$ & $\ldots$ & $\ldots$ & $\ldots$ & 1 \\
\hline \multirow[t]{3}{*}{$5(1 \mathrm{H})$} & 50 to 60 & $\ldots$ & $\ldots$ & $\ldots$ & $\begin{array}{l}\cdots \\
\cdots\end{array}$ & $\begin{array}{l}\cdots \\
\cdots\end{array}$ & $11^{\mathrm{f}}$ & $\begin{array}{l}\cdots \\
\ldots\end{array}$ & $\begin{array}{l}\cdots \\
\cdots\end{array}$ & 1 \\
\hline & 90 to 100 & $\ldots$ & $\ldots$ & $\ldots$ & $\ldots$ & $\ldots$ & $\ldots$ & 3 & $\ldots$ & 1 \\
\hline & 110 to 122 & $\ldots$ & $\ldots$ & $\ldots$ & & & $\ldots$ & $\ldots$ & $2.8^{\mathrm{g}}$ & 1 \\
\hline \multirow[t]{2}{*}{$6(6 \mathrm{H})$} & 50 to 65 & $\ldots$ & $\ldots$ & 11 & 5.7 & 2.5 & $\ldots$ & 6.4 & 5.5 & 5 \\
\hline & 40 to 50 & $\ldots$ & $\ldots$ & $\ldots$ & $\ldots$ & $\ldots$ & $\ldots$ & $4.5^{\mathrm{g}}$ & $\ldots$ & 1 \\
\hline \multirow[t]{2}{*}{$7(5 \mathrm{H})$} & 120 to 130 & $\ldots$ & $\ldots$ & $\ldots$ & $\ldots$ & 3.5 & 6 & $\ldots$ & $\ldots$ & 2 \\
\hline & 155 to 170 & $\ldots$ & $\ldots$ & $\ldots$ & $\ldots$ & 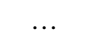 & $\ldots$ & $4.2^{\mathrm{g}}$ & $3.5^{\mathrm{g}}$ & 2 \\
\hline Total chr. & $\ldots$ & 3 & 3 & 5 & 2 & 7 & 4 & 6 & 3 & $\ldots$ \\
\hline
\end{tabular}

${ }^{a}$ LOD value 2.7 and higher is considered to be a quantitative trait locus (QTL). Regions with LOD values between 2 and 2.7 (highlighted in bold) were included only when they were implicated in resistance to other rust fungi.

${ }^{\mathrm{b}}$ P.hor $=$ Puccinia hordei, P.hor-mur $=$ P. hordei-murini, P.tri $=$ P. triticina, P.duri $=$ P. triticina- “duri”, P.per $=$ P. persistens, P.hor-sec $=P$. hordei-secalini, P.gram-tri $=P$. graminis f. sp. tritici, P.gram-lol $=P$. graminis $\mathrm{f}$. sp. lolii, and Total $=$ total number of rusts.

${ }^{\mathrm{c}}$ Locations of affecting regions: $\mathrm{Chr} .=$ chromosome, Pos. = position in centimorgans $(\mathrm{cM})$, and Total chr. $=$ total number of chromosomal regions.

${ }^{\mathrm{d}}$ Results for three isolates (collected in the Netherlands, France, and Switzerland) identified the same QTLs with similar LOD scores. Here, we present the data obtained for the Flamingo isolate.

e This QTL was found to be effective on Flamingo and not on the two other isolates.

${ }^{\mathrm{f}}$ The qualitative segregation for hypersensitivity against $P$. hordei-secalini allowed mapping of this feature by Joinmap. This demonstrated that the QTL at 50 to $60 \mathrm{cM}$ on chromosome $5(1 \mathrm{H})$ was responsible for the hypersensitive reaction.

${ }^{\mathrm{g}}$ QTLs with resistance allele contributed by SusPtrit. 
ized on some of the new species, loosing pathogenicity to some sibling species (Heath 1991). In such an evolutionary radiation, speciation in the grass family and rusts is likely to take place simultaneously. In that case, we would expect either that i) plant QTLs determining the feasibility for being a host for a rust pathogen tend to be effective to taxonomically related rusts or ii) such QTLs are effective to rusts that share the same host species.

Seven rust species used in the present study belong to three different groups of rust fungi of grasses: $P$. hordei, $P$. persistens/ $P$. triticina, and $P$. graminis group containing two, three, and two rust species, respectively. Our evidence of such an evolutionary association is inconclusive. Some QTLs are effective to two closely related rust species (e.g., $P$. triticina and $P$. persistens); others to two rusts that are pathogenic to the same host (e.g., P. triticina and $P$. graminis f. sp. tritici); but others, however, to two less-related rust species on less-related host species (e.g., P. hordei and P. persistens). Hence, our data do not confirm a tendency for QTLs to be effective to rusts that have a close phylogenetic relationship. Our data further illustrate that evolutionary distance and host status to a certain potential pathogen are not associated, either. For example, the rusts $P$. allii and $P$. holci are closely related to $P$. hordei, but cannot infect barley, not even the experimental line SusPtrit (data not presented). Two moderately related rusts, $P$. cerinthes-agropyrina and $P$. persistens, both can infect Elytrigium repens, but only the latter is also able to infect SusPtrit. Therefore, it is likely that biological specialization in biotrophic fungi, such as rust pathogens of grasses and cereals, is influenced by some other factors, such as geographical origin of pathogens, as reviewed by Wyand and Brown (2003).

\section{Possible nature of the QTL genes.}

The extreme susceptibility of SusPtrit suggests that it is deficient for some key gene or genes in signal transduction or defense response to rust fungi. However, this barley line is well able to prevent haustorium formation by rye leaf rust (data not shown) and also is immune to several other rusts (Atienza et al. 2004). Also, it is unlikely that each heterologous rust elicits different transduction pathways or defense
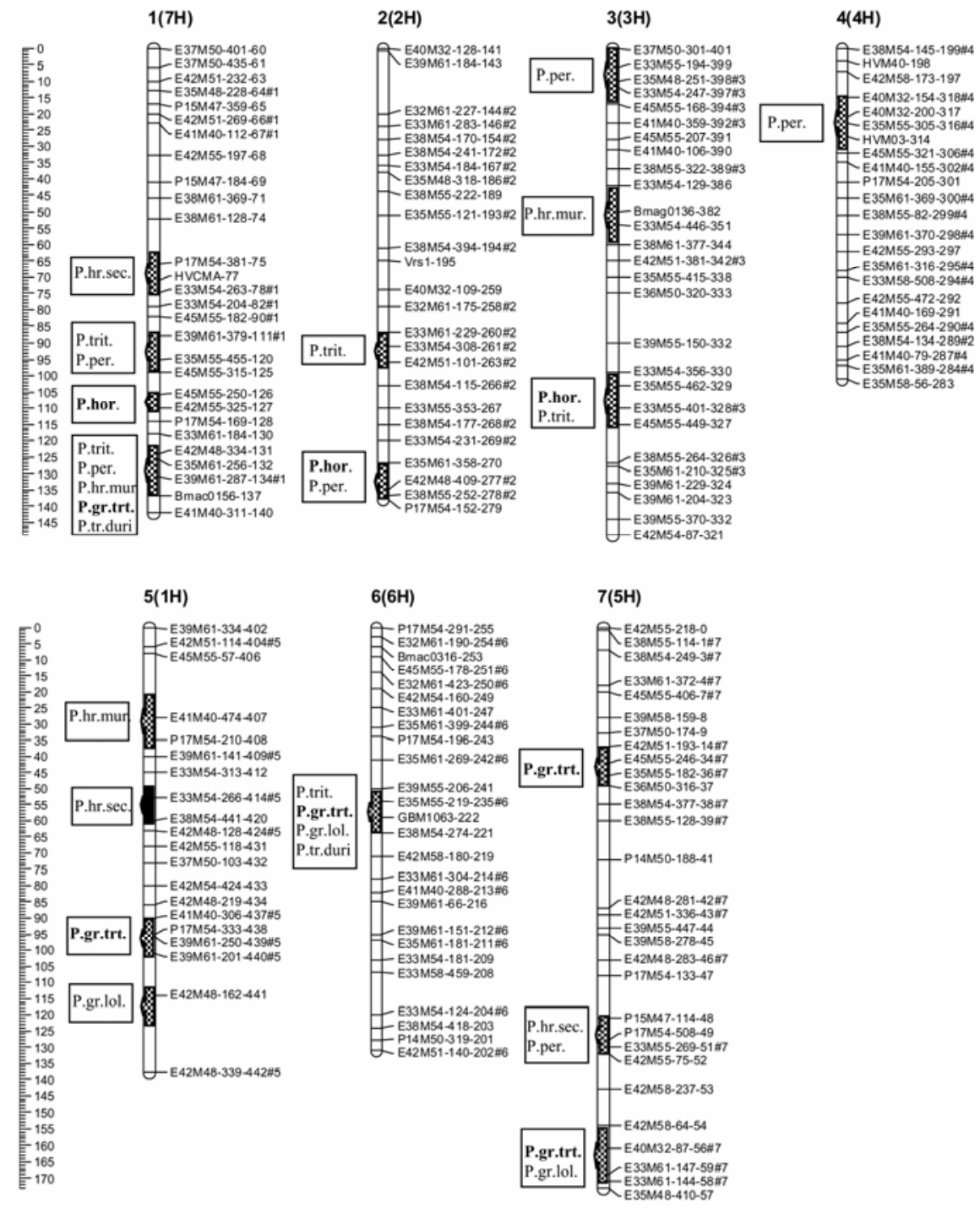

Fig. 4. Locations of quantitative trait loci (QTLs) mapped for host and nonhost resistance to eight rust species and isolates in barley mapping population Vada $\times$ SusPtrit (P.trit. = Puccinia triticina Flamingo isolate, P.pers. $=$ P. persistens, P.hor. $=$ P. hordei, P.hr.sec. $=$ P. hordei - secalini, P.hr.mur. $=$ P. hordeimurini, P.gr.trt. $=$ P. graminis f. sp. tritici, P.gr.lol $=$ P. graminis $\mathrm{f}$. sp. lolii, and P.tr.duri $=$ P. tirticina from Triticum durum ). QTL bars indicate approximate position of two log of the likelihood ratio support intervals and the ruler at the left margin shows the distance in centimorgans. QTLs effective to host pathogens are highlighted in bold, shaded bars indicate QTL with single or multiple effects; and black bars indicate QTL that coincide with the major gene to P. hordei-secalini. 
genes, especially not when the rusts are more or less related to each other. Although some other scenarios are conceivable, we presume that the genes at the QTLs described here encode for proteins that play a role as specific and quantitative recognition factors that should be specifically negated by effectors delivered by the rust to successfully suppress basal defense. Such a role, but not necessarily their molecular identity, could be comparable to that of HR inducer $R$ genes that interact with specific $A V R$ factors produced by the pathogens.

\section{MATERIALS AND METHODS}

Development of the mapping population.

A barley research line that is in the seedling stage fully susceptible to $P$. triticina and to some other heterologous rusts, named SusPtrit (Atienza et al. 2004), was crossed with the West European cv. Vada. The latter accession represents "normal" barley, which is fully resistant to heterologous rusts (Atienza et al. 2004) and has several QTLs for partial resistance to P. hordei (Qi et al. 1998b). After seven generations of single-seed decent from $200 \mathrm{~F}_{2}$ plants, a population of $152 \mathrm{~F}_{8^{-}}$ derived RILs was obtained.

\section{DNA extraction and molecular marker analysis.}

Genomic DNA of the 152 RILs and the parents (SusPtrit and Vada) was isolated from fresh leaves according to the cetyltrimethylammonium bromide (CTAB)-based protocol of Steward and Via (1993) adjusted for a 96-well format. The AFLP procedure was performed according to the two-step amplification as described by Vos and associates (1995) with some minor modifications. In this study, 25 EcoRI/MseI primer combinations, each with three selective nucleotides, and three Pst $\mathrm{I} /$ MseI primer combinations with two selective nucleotides were used to generate the AFLP markers. The scoring of the AFLP products was based on absence or presence of amplification products. Segregating markers showing polymorphism between two parents were scored in the mapping population by using Quantar-Pro software (Keygene, Wageningen, The Netherlands). In addition, the RILs were genotyped for 12 polymorphic SSR markers.

\section{Linkage analysis and map construction.}

Linkage analysis was carried out with JoinMap 3.0 (Kyazma B.V., Wageningen, The Netherlands) and Kosambi's function was used for map distance calculation. Linkage groups were assigned to the respective barley chromosomes by morphological markers, SSR markers, and 152 common AFLP markers that already had been mapped by (Qi et al. 1998a) in the L94 $\times$ Vada mapping population. In case of ambiguity, the freely available software program RECORD (Van Os et al. 2005) was used to find the most probable order of the loci on the linkage maps on the basis of recombination events (RECORD software is available online from the Laboratory of Plant Breeding, Wageningen University). A subset of 179 markers was extracted for use in a skeleton map for QTL mapping. The selection was based on spacing of the markers at approximately 5 to $10 \mathrm{cM}$ and agreement between RECORD and Joinmap results on their relative position.

\section{Pathogen material.}

Ten isolates of rust fungi were used in infection studies. $P$. triticina of bread wheat (three isolates), P. triticina of durum wheat (labeled for convenience " $P$. triticina "duri"), $P$. persistens (= P. agropyrina) $P$. hordei-murini, $P$. hordei-secalini, and

Table 3. Rust isolates used in this study

\begin{tabular}{|c|c|c|c|c|}
\hline Rust $^{\mathbf{a}}$ & Host & Collections $^{\mathrm{b}}$ & Location & GenBank accession no. \\
\hline Puccinia allii & Allium porrum & MS 165/62 & Germany & $\mathrm{AY} 187090^{\circ}$ \\
\hline P. allii & A. sativum & YA8799 & Turkey & AF511073 \\
\hline P. bromina & Bromus sterilis & $\mathrm{RN}-13$ & The Netherlands & DQ460719 \\
\hline P. cerinthes-agropyrina & Elytrigia sp. & RN-9 & Spain & DQ460720 \\
\hline P. coronata f. sp. avenae & Avena sativa & CDL93MN437 & United States & AY114290 \\
\hline P. coronata f. sp. lolii & Lolium perenne & PRC 202 & Czech Republic & DQ460728 \\
\hline P. graminis. f. sp. lolii & L. perenne & $\mathrm{RN}-1$ & The Netherlands & DQ460726 \\
\hline P. graminis f. sp. tritici & Triticum aestivum & CDL 62ND72C & United States & DQ460725 \\
\hline$P$. graminis f. sp. tritici & Triticum aestivum & $\mathrm{HUN}^{\mathrm{d}}$ & Hungary & \\
\hline P. graminis $\mathrm{f}$. sp. avenae & A. sativa & $\mathrm{RN}-20$ & Hungary & DQ460727 \\
\hline P. holcina & Holcus lanatus & PRC 159 & Czech Republic & DQ512999 \\
\hline P. holcina & H. mollis & $\mathrm{RN}-5$ & The Netherlands & DQ513000 \\
\hline P. hordei isolate 1.2.1 & Hordeum vulgare & $\mathrm{RN}-17$ & The Netherlands & DQ460717 \\
\hline P. hordei-murini & H. murinum & $\mathrm{RN}-4$ & The Netherlands & DQ460718 \\
\hline P. hordei-murini ${ }^{\mathrm{f}}$ & H. murinum & Aragon & Spain & \\
\hline P. hordei-secalini & H. secalinum & RN-3 & France & DQ460723 \\
\hline P. persistens & Elytrigia repens & PRC 227 & Ireland & DQ460722 \\
\hline P. persistens & E. repens & $\mathrm{RN}-8$ & The Netherlands & DQ460721 \\
\hline P. striiformis $\mathrm{f} . \mathrm{sp}$. hordei & Hordeum vulgare & HSZ0711 & United States & DQ460729 \\
\hline P. striiformis f. sp. tritici & T. aestivum & HSZ0718 & United States & DQ417401 ${ }^{\mathrm{e}}$ \\
\hline P. triticina & T. aestivum & CDL00LA87 & United States & AF511083 \\
\hline P. triticina & T. aestivum & Flamingo & The Netherlands & $\ldots$ \\
\hline P. triticina & T. aestivum & Swiss & Switzerland & $\ldots$ \\
\hline P. triticina & T. aestivum & French & France & $\ldots$ \\
\hline P. triticina-duri & T. turgidum subsp. durum & $\mathrm{RN}-22$ & Spain & DQ460724 \\
\hline
\end{tabular}

${ }^{a}$ Rust isolates used for quantitative trait locus (QTL) analysis are highlighted in bold. Remaining isolates were included either to determine phylogenetic distance of rusts in relation to their host or for increasing of stability of parsimony tree obtained from analysis of internal transcribed spacer sequence data. Scientific names of rusts are used as convenient labels and do not necessarily reflect the taxonomic status of the rusts.

${ }^{\mathrm{b}}$ Prefix designations and sources for collections: MS = Markus Scholler, Staaliches Museum für Karlsruhe, Karlsruhe, Germany; YA = Y. Anikster, Institute for Cereal Crop Improvement, Tel Aviv University, Israel; RN = Rients Niks; CDL = Cereal Disease Laboratory, United States Department of AgricultureAgricultural Research Service HSZ, L. J. Szabo; and PRC = J. Marková, Charles University, Prague, Czech Republic.

${ }^{c}$ Anikster and associates (2004).

${ }^{\mathrm{d}}$ Provided by K. Manninger from Plant Protection Institute, Budapest, Hungary.

${ }^{\mathrm{e}}$ C. W. Barnes and L. Z. Szabo, unpublished data.

${ }^{\mathrm{f}}$ The same QTLs were identified for both $P$. hordei-murini isolates. 
$P$. graminis f. sp. lolii were multiplied on their respective host plants (Atienza et al. 2004). P. hordei (isolate 1.2.1) and $P$. graminis f. sp. tritici were increased using the susceptible barley line L98 and wheat cv. Morocco, respectively. Urediniospores were collected, dried for 2 to 7 days, and then stored at $-80^{\circ} \mathrm{C}$ until the time to be used for inoculation.

\section{Phenotyping of the mapping population for resistance to heterologous rust fungi.}

Seedlings of RILs were grown in boxes ( 37 by $39 \mathrm{~cm}$ ) along with both parents and susceptible host plants. Twelve days after sowing, completely unfolded primary leaves were placed in a horizontal position with the adaxial side facing up and inoculated with approximately $10 \mathrm{mg}$ of spores per box (deposition of approximately 600 urediniospores $/ \mathrm{cm}^{2}$ ) using a settling tower (Atienza et al. 2004). After inoculation, the plants were incubated overnight in a dew chamber for $10 \mathrm{~h}$ (17 to $18^{\circ} \mathrm{C}, 100 \%$ relative humidity, without light) and then transferred to a greenhouse $\left(22^{\circ} \mathrm{C}\right.$ day and $18^{\circ} \mathrm{C}$ night $)$. Twelve days after inoculation, the level of infection was quantified by estimating the FVIS and two additional parameters, IF and RIF. The test was performed in three consecutive replications, except in the case of $P$. graminis f. sp. tritici and $P$. triticina"duri", where phenotyping was carried our in two replications. The quantitative data for each replication and the average of three replications were used as phenotypic values for QTL mapping.

\section{Phenotyping of the mapping population for resistance to host rust fungi.}

The RILs were grown as described above and tested for level of partial resistance to $P$. hordei (isolate 1.2.1) as described by Qi and associates (1998b). The latency period (LP) of each plant was evaluated by estimating the time (in hours) at which $50 \%$ of the ultimate number of pustules were visible. The RLP of seedlings was calculated relative to the LP of L94 plants as described by Parlevliet (1975). The average over three replications was considered to reflect the level of partial resistance of each RIL. For $P$. graminis f. sp. tritici, only $5 \mathrm{mg}$ of spores were used per box. $P$. graminis f. sp. tritici often formed large pale green halos around the uredinia and adjacent halos frequently merged; therefore, total leaf area covered by these halos was used as the parameter for QTL mapping.

\section{QTL mapping.}

The software Map QTL (version 5.0; Kyazma B.V.) was used to perform QTL mapping. A permutation test was applied to determine the LOD value for both chromosome-wide and genome-wide significance threshold at level of 5\%. By interval mapping, putative QTLs were detected on each set of disease data and were verified by application of multiple-QTL mapping (MQM). In the region of putative QTLs, the peak markers with the highest LOD value were selected as cofactors for running MQM (Jansen and Stam 1994). Only those QTLs that occurred in three replications and in the average over those replications were considered to be reliable QTLs. Regions that were implicated in resistance at LOD values 2.0 to 2.7 were considered potentially real only when the same chromosomal region reached significant LOD values with at least one other rust species.

\section{ITS sequences of rust fungi.}

DNA was extracted from either dried urediniospores collected from infected host material or from dried infected host leaf tissue as described by Anikster and associates (2004). In some cases, an OminiPrep (Genotech, St. Louis) DNA extraction kit was used instead of the CTAB DNA extraction method.
The nuclear ribosomal ITS region and the $5^{\prime}$ end of the large subunit were amplified using polymerase chain reaction, and amplification products were cloned (Anikster et al. 2004). Primer pairs used for amplification were ITS1F (Gardes and Bruns 1993) and RUST1 (Kropp et al. 1995). DNA sequencing reactions were performed using a Thermo Sequenase Primer Cycle sequencing kit (GE Healthcare Bio-Sciences Corp., Piscataway, NJ, U.S.A.) and analyzed on an automated DNA sequencer (LI-COR, Lincoln, NE, U.S.A.). At least three clones were sequenced for each sample and the DNA sequence was assembled and edited with Sequencer (Gene Codes Corp., Ann Arbor, MI, U.S.A.). DNA sequences initially were aligned using the program CLUSTAL W (Thompson et al. 1994) and then hand edited using the multiple sequence editor in MacVector (version 7.2.3; Accelrys Inc. San Diego, CA, U.S.A.). Approximately $1,250 \mathrm{bp}$ of DNA was sequenced for each sample, including the $3^{\prime}$ end of the nuclear ribosomal 18S subunit, the complete ITS region (ITS1, 5.8S, and ITS2), and the 5' end of the $28 \mathrm{~S}$ subunit, providing an aligned sequence of 1,367 characters. Variation in the $5^{\prime}$ end of the $28 \mathrm{~S}$ subunit was low and, therefore, not included in the phylogenetic analysis. Of the 664 aligned characters analyzed, 510 were constant, 148 were variable and parsimony-informative, and 6 were variable and parsimony-uninformative Phylogenetic analysis of the data sets included the complete ITS1, 5.8S, and ITS2 region and was carried out using a neighbor-joining and heuristic parsimony program (PAUP, version 4.04b10) (Swofford 2001). Support for the nodes of the trees was determined by analysis of 1,000 bootstrap replicas.

Phylogenetic analysis in the present study was performed based on the ITS sequence of 20 rust species and forms (Table 3 ), from which seven species were applied for phenotyping of RILs and QTL mapping.

\section{ACKNOWLEDGMENTS}

H. Jafary was financially supported by the Agricultural Research and Education Organization (AREO) and Ministry of Science Research and Technology of Islamic Republic of Iran. We thank T. Marcel for his help in construction of the genetic map and A. Vels for his technical assistance. N. Stein from the Institute of Plant Genetics and Crop Plant Research (IPK) is acknowledged for providing some primer sequences for the construction of the linkage map. R. Visser and E. van der Vossen are acknowledged for critically reading the manuscript and for their valuable comments.

\section{LITERATURE CITED}

Anikster, Y., Szabo, L. J., Eilam, T., Manisterski, J., Koike, S. T., and Bushnell, W. R. 2004. Morphology, life cycle biology, and DNA sequence analysis of rust fungi on garlic and chives from California. Phytopathology 94:569-577.

Atienza, S. G., Jafary, H., and Niks, R. E. 2004. Accumulation of genes for susceptibility to rust fungi for which barley is nearly a nonhost results in two barley lines with extreme multiple susceptibility. Planta 220:7179.

Gardes, M., and Bruns, T. D. 1993. ITS primers with enhanced specificity for basidiomycetes-application to the identification of Mycorrhizae and rusts. Mol. Ecol. 2:113-118.

Gomez-Gomez, L., and Boller, T. 2000. FLS2: An LRR receptor-like kinase involved in the perception of the bacterial elicitor flagellin in Arabidopsis. Mol. Cell 5:1003-1011.

Heath, M. C. 1991. Evolution of resistance to fungal parasitism in natural ecosystems. New Phytol. 119:331-343.

Hoogkamp, T. J. H., Chen, W. Q., and Niks, R. E. 1998. Specificity of prehaustorial resistance to Puccinia hordei and to two inappropriate rust fungi in barley. Phytopathology 88:856-861.

Jansen, R. C., and Stam, P. 1994. High-Resolution of quantitative traits into multiple loci via interval mapping. Genetics 136:1447-1455.

Jeuken, M., and Lindhout, P. 2002. Lactuca saligna, a nonhost for lettuce downy mildew (Bremia lactucae), harbors a new race-specific Dm gene and three QTLs for resistance. Theor. Appl. Genet. 105:384-391.

Kang, L., Li, J. X., Zhao, T. H., Xiao, F. M., Tang, X. Y., Thilmony, R., He, 
S. Y., and Zhou, J. M. 2003. Interplay of the Arabidopsis nonhost resistance gene NHO1 with bacterial virulence. Proc. Natl. Acad. Sci. U.S.A. 100:3519-3524.

Kim, M. G., da Cunha, L., McFall, A. J., Belkhadir, Y., DebRoy, S., Dangl, J. L., and Mackey, D. 2005. Two Pseudomonas syringae type III effectors inhibit RIM-regulated basal defence in Arabidopsis. Cell 121:749759

Kropp, B. R., Albee, S., Flint, K. M., Zambino, P., Szabo, L., and Thomson, S. V. 1995. Early detection of systemic rust infections of dyers-woad (Isatis-Tinctoria) using the polymerase chain-reaction. Weed Sci. 43:467-472.

Kunze, G., Zipfel, C., Robatzek, S., Niehaus, K., Boller, T., and Felix, G. 2004. The $\mathrm{N}$ terminus of bacterial elongation factor $\mathrm{Tu}$ elicits innate immunity in Arabidopsis plants. Plant Cell 16:3496-3507.

Liu, Z. W., Biyashev, R. M., and Maroof, M. A. S. 1996. Development of simple sequence repeat DNA markers and their integration into a barley linkage map. Theor. Appl. Genet. 93:869-876.

Lu, M., Tang, X. Y., and Zhou, J. M. 2001. Arabidopsis NHO1 is required for general resistance against Pseudomonas bacteria. Plant Cell 13:437447.

Mellersh, D. G., and Heath, M. C. 2001. Plasma membrane-cell wall adhesion is required for expression of plant defence responses during fungal penetration. Plant Cell 13:413-424.

Niks, R. E. 1983. Haustorium formation by Puccinia hordei in leaves of hypersensitive, partially resistant, and nonhost plant genotypes. Phytopathology 73:64-66.

Niks, R. E. 1986a. Failure of haustorial development as a factor in slow growth and development of Puccini hordei in partially resistant barley seedlings. Physiol. Mol. Plant Pathol. 28:309-322.

Niks, R. E. 1986b. Variation of mycelial morphology between species and special forms of rust fungi of cereals and grasses. Can. J. Bot.-Rev. Can. Bot. 64:2976-2983.

Niks, R. E. 1989. Induced accessibility and inaccessibility of barley cells in seedling leaves inoculated with 2 leaf rust species. J. Phytopathol.Phytopathol. Z. 124:296-308.

Niks, R. E., and Dekens, R. G. 1991. Prehaustorial and posthaustorial resistance to wheat leaf rust in diploid wheat seedlings. Phytopathology 81:847-851.

Niks, R. E., and Rubiales, D. 2002. Potentially durable resistance mechanisms in plants to specialised fungal pathogens. Euphytica 124:201-216.

Panstruga, R. 2003. Establishing compatibility between plants and obligate biotrophic pathogens. Curr. Opin. Plant Biol. 6:320-326.

Parlevliet, J. E. 1975. Partial resistance of barley to leaf rust, Puccinia hordei . 1. Effect of cultivar and development stage on latent period. Euphytica 24:21-27.

Qi, X., Niks, R. E., Stam, P., and Lindhout, P. 1998a. Identification of QTLs for partial resistance to leaf rust (Puccinia hordei) in barley. Theor. Appl. Genet. 96:1205-1215.
Qi, X., Stam, P., and Lindhout, P. 1998b. Use of locus-specific AFLP markers to construct a high-density molecular map in barley. Theor. Appl. Genet. 96:376-384.

Ramsay, L., Macaulay, M., Ivanissevich, S. D., MacLean, K., Cardle, L., Fuller, J., Edwards, K. J., Tuvesson, S., Morgante, M., Massari, A., Maestri, E., Marmiroli, N., Sjakste, T., Ganal, M., Powell, W., and Waugh, R. 2000. A simple sequence repeat-based linkage map of barley. Genetics 156:1997-2005.

Steward, C. N., and Via, L. E. 1993. A rapid CTAB DNA isolation technique useful for RAPD fingerprinting and other PCR applications. Biotechniques 14:748-750.

Swofford, D .L. 2001. PAUP*. Phylogenetic Analysis Using Parsimony (*and other methods). Sinauer Associates, Sunderland, MA, U.S.A.

Thompson, J. D., Higgins, D. G., and Gibson, T. J. 1994. Clustal-W-improving the sensitivity of progressive multiple sequence alignment through sequence weighting, position-specific gap penalties and weight matrix choice. Nucleic Acids Res. 22:4673-4680.

Thordal-Christensen, H. 2003. Fresh insights into processes of nonhost resistance. Curr. Opin. Plant Biol. 6:351-357.

Van Os, H., Stam, P., Visser, R. G. F., and Van Eck, H. J. 2005. RECORD: A novel method for ordering loci on a genetic linkage map. Theor Appl. Genet. 112:30-40.

Vos, P., Hogers, R., Bleeker, M., Reijans, M., Vandelee, T., Hornes, M., Frijters, A., Pot, J., Peleman, J., Kuiper, M., and Zabeau, M. 1995. AFLP-A new technique for DNA-fingerprinting. Nucleic Acids Res. 23:4407-4414.

Wildermuth, M. C., Dewdney, J., Wu, G., and Ausubel, F. M. 2001. Isochorismate synthase is required to synthesize salicylic acid for plant defence. Nature 414:562-565.

Wyand, R. A., and Brown, J. K. M. 2003. Genetic and forma specialis diversity in Blumeria graminis of cereals and its implications for hostpathogen co-evolution. Mol. Plant Pathol. 4:187-198.

Zhang, H. S., Delarosa, R., Rubiales, D., Lubbers, H. H., Molenveld, J. W., and Niks, R. E. 1994. Role of partial resistance to Puccinia hordei in barley in the defence of barley to inappropriate rust fungi. Physiol. Mol. Plant Pathol. 45:219-228.

Zipfel, C., and Felix, G. 2005. Plants and animals: A different taste for microbes? Curr. Opin. Plant Biol. 8:353-360.

Zipfel, C., Kunze, G., Chinchilla, D., Caniard, A., Jones, J. D. G., Boller, T., and Felix, G. 2006. Perception of the bacterial PAMP EF-Tu by the receptor EFR restricts Agrobacterium-mediated transformation. Cell 125:749-760

\section{AUTHOR-RECOMMENDED INTERNET RESOURCE}

Department of Plant Breeding, Wageningen University RECORD software: www.dpw.wau.nl/pv/index.htm

\section{Erratum}

Due to a technological malfunction that occurred during final layout, several words were misspelled in the abstract. The online version was corrected on October 25, 2006. 